\title{
Behavior Pathology on Gender Issues in Nigeria Banks Employment: Myths and Realities
}

\author{
Continue Anddison Eketu, $\mathrm{PhD}$ \\ Department of Management, University of Port Harcourt
}

\begin{abstract}
The paper examined the myths and realities on gender issues in Nigeria banks employment. The study collected data from a sample of 648 employees of deposit money bank headquarters in Port Harcourt. The research data were treated to primary analysis involving descriptive statistics of respondents' demographics and workplace factors concerning workers outcomes. The demographics were presented in pie charts, while the workplace factors were presented in their mean scores. The study perceived that the discrimination in banks employment, which is in favour of young unmarried girls, is a mere response to societal sex-role creation in feminism and masculinism, clothed in corporate immorality. This is perceived to be strong in generating sex appeal, coquetry, flattery, and pandering to male egoism. The paper thus suggested a three phase model to reduce the expanding margin in the gender dichotomy in banks employment.
\end{abstract}

Keywords: Gender Issues, Bank Employment, Sex Roles, Feminism, Masculinism, Behaviour Pathology and Corporate Immorality.

DOI: $10.7176 / \mathrm{EJBM} / 11-8-05$

Publication date:March $31^{\text {st }} 2019$

\section{Introduction}

Cries on gender related issues particularly as it pertain to discrimination against women is almost global. The worries appear to be more about Africa and Asia where modern social civilization has not taken a commendable leap away from repugnant tradition against women (Ines, Yap \& Whiting, 2013; Mason, Czajka \& Arber, 2000; and Kottak, 2014). On this note, there have been notable convergence of ideas and efforts across the globe amongst women, with men lending their voices to support the call for gender equality (Villamez, 2001; and Ines, Yap \& whiting, 2013). For this reason, international organizations, non-governmental organization and governments and their agencies have all joined in the campaign to rescue the female gender from perceived or real relegation from the scheme of active existence (Hyde, 2016; Black \& Holden, 1998; Hewlett \& Rashid, 2010).

However, a paradigm in bank workers employment in Nigeria, particularly after the bank distress-syndrome, resulting to post consolidation era has posed a burden of intellectual obligation for critical behavior pathology. In this paradigm, it is viewed that the post consolidation banking in Nigeria has had more women recruited into the industry in a ratio that is conspicuously disfavourable to men. Agundu (2006) observed this trend in his "corporate womanization of Nigeria banks", and suggested that the phenomenon explains away the presumed axiologies and stereotypes of gender-job fitness. Nevertheless, if the vocational engagements, deployment and challenges of those recruited are to be viewed with some seriousness, then it may most likely reveal that there is more to be known about the sex-role implications, as it affect culturally created expectations of feminism and masculinism in the word of walks, as it is in Chance (1988).

Notwithstanding, that the trend appears to be more or less an established order in banks recruitment and deployment pattern, very little is reportedly known about gender-job fitness with respect to such organization variables as performance, intention to stay, commitment, work passion, absenteeism, and deviant behaviours in the banking industry. This paper empirically examines these issues to provide a means of classifying thoughts, to separate myths from realities in corporate behavior on feminism and masculinism in Nigerian banks.

\section{Literature Review \\ The Concepts of Gender and Sex}

There is a growing etymological consciousness that sex and gender do not mean exactly the same thing, even as the two concepts are used synonymously (Basow, 2000). Sex is a biological concept used to categorize the natural difference between man and woman. Thus, it is a societal view on sex categories, and it is certainly male or female.

Eketu (2018:1) contended that sex is viewed as a biological term referring to objective realities of male and female. This places the natural existence of biological and anatomical difference between males and female beings. On the contrary, gender is a concept which developed from the existence and consciousness of society on sex difference. Basow (2000) thus, enunciated that clearly, distinction between sex and gender bear biological and psycho-sociological bases and inclinations. For instance, Eketu (2018) furthered in his argument on sex-gender etymological dichotomy that “... while gender is a psycho-social and cultural term, referring to a society's subjective feelings of a human beings, maleness and femaleness. Thus from a socio-anthropological view point, gender tends to imply an expression of a society's evaluation of behavioural attributes as masculine or feminine. 
It is therefore in the view of Eketu (2018:1) that "from analytical consideration, sex relates to experiential reality, while gender relates to agreement reality". Thus, the difference between sex and gender is found in nature (sex) and consciousness (gender). Unfortunately, meanings derived from the nature and consciousness of sex and gender are very often clothed with stereotypes which deride perceptual accuracies of individuals.

\section{Gender and Work Attributes}

Decisions on gender and work attributes are replate in workplace management and organizational behavior theorizing. Such issues as: talent, commitment, consciousness, civic virtue, emotional stability, productivity, etc are contextual and contended (Eketu, 2018; Westen, 2000; Kottak, 2014 and Hyde, 2016). Although, Robbins and Sanghi (2010:41) view that, "few issues initiate more debates, misconceptions, and unsupported opinions than whether women perform as well on jobs as men do" ... the evidence suggest that in the recognition there are few, if any important differences between men and women that will affect their job performance". For instance, Eagly \& Carli (2009) observed no consistent male-female difference in problem-solving ability, analytical skills, competitive drive, motivation, sociability, or learning ability.

Nevertheless, Hyde (2016) found from psychological studies that women are more obedient to authority, while men are more optimistically aggressive in the expectation of success. However, there exists minority significance in the observed differences, between male and female workplace outcomes. But more critically, considering the burden of societal pressure on gender models expected in feminism and masculinism, it may be misleading to contend variance may only exist on physical strength and natural endowments than psychological and mental capacities. For instance, societal mental models for sex roles have casted a mould in which feminine and masculine categories adjust to fit in, to remain relevant and acceptable to society (Chafetz, 1978; Basow, 2000; and Eketu, 2018).

The direction of the argument almost roughly corresponds to battle for female talent in emerging markets (Hewlett \& Rashid, 2010) and arguments on gender and racial differentials in Nigerian banking industry as put further by Iyiola \& Iyiola (2009). Thus, to say that no gainful difference exist between gender on work variables, is to concur that gender discrimination in workplace management is fallacious, which do not appear truly to hold sway in all considerations.

\section{Gender Issues in Nigerian Banks}

Beside hotels, banks have attracted more discussion on gender considerations than any work category. With quite an unrelated vocational typology, that the issue of gender consideration or attraction is share in almost the same concern in both banks and hotels is yet another object for research investigations. In Nigeria, particularly from the post banks consolidation epoch, dramatic changes have been observed in banks handling of gender concerns (Agundu, 2006; and Iyiola \& Iyiola, 2009).

The corporate behavior trends observed with respect to gender appears to be female gender friendly, with a proportion that is conspicuous enough to attract research lens. For instance more women of younger ages are recruited into the bank with an insignificance number of males. More banks top executives are now women, but in the context of this geometric expulsion in female workforce in the banks, more men are retrenched, dismissed or retired (Otuchikere \& Ifeakundu, 2010). Given this dramatic and drastic progression, Agundu (2006) reported on the corporate womanization of banks in Nigeria as a scenario that is unprecedented. Agundu noted that it appears that banks are poised to maintain a near gender homogeneity in the favour if woman. The concentration of women is dominantly in interface functions such as marketing operations and bank floor functions (tellers and cashiers). The trend signifies stereotypic tendencies (Eketu, 2018) but with no clear basis as to the rationale or criteria for the lopsided trend. It is rather contextual to consider the disproportionate trends particularly in employment, as a talent or endowment hunt.

\section{Methodology}

The study adopted a cross sectional survey research design, and collected data from 24 banks headquarters situated in Port Harcourt. The data collection instrument were structured questionnaire and interview. The instrument reliability test was Crombach Alph, where all coefficients were found to be above the threshold of 0.7. The univariate and bi-variates analysis were used to present the research data and test of the formulated research hypotheses, respectively. The study utilized methodological pluralism involving mixed methods. For research ethical reasons, the identity of the banks and individual employees involved in this study are not disclosed. 
Data Presentation and Analysis Figure 1: Pie Chart on Sex Distribution

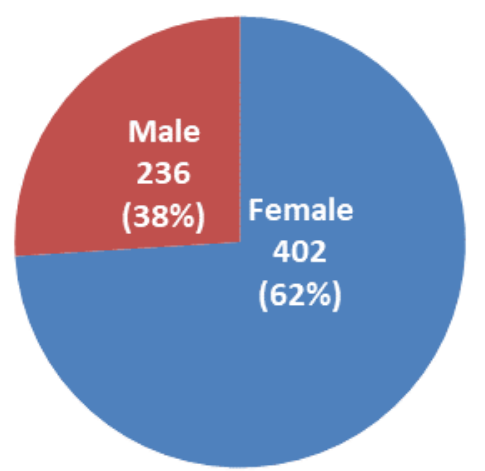

The pie chart above represents the sex distribution of employees in 24 banks headquarters in Port Harcourt. It shows a total number of 648 employees, $402(62 \%)$ are females, while $236(38 \%)$ are males. The female bank employees $162(25 \%)$ above the males.

Figure 2: Pie Chart on Marital Status Distribution

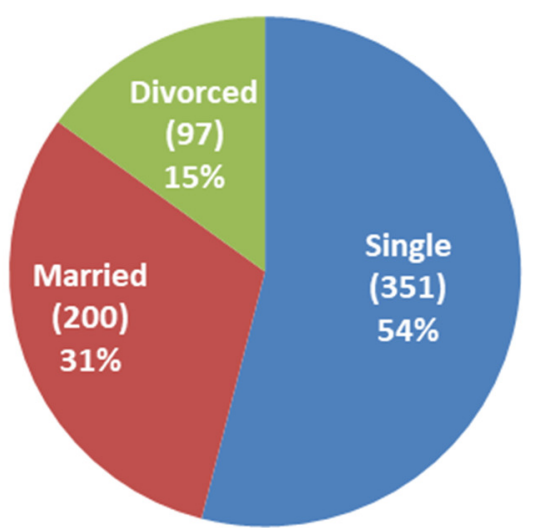

The marital status of bank employees is presented in figure 2. The pie chart show a distribution of 351 (single), 200 (married) and 97 (divorced) employees. The number of single bank employee is 151 employees above the married category, and 254 employees above the divorced/widow category.

Figure 3: Pie Chart on Age Distribution

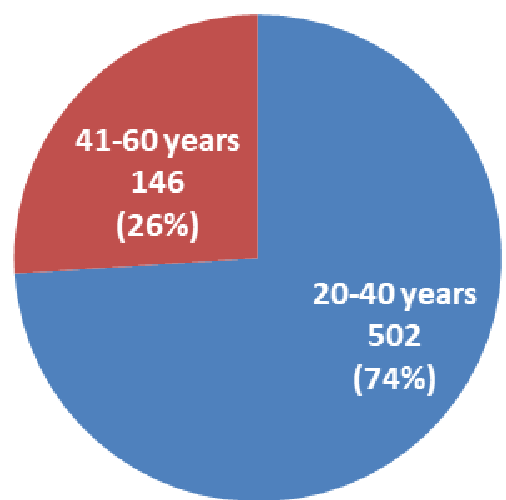

The age distribution of bank employees is presented in figure 3. The distribution shows that out of the 648 employees, 502 are with the age category between $20-40$ years, and 146 fall within the age category of $41-60$ years. This indicates that banks employees are dominantly people of younger ages. 
Table 1: Mean Scores of Organizational Variables

\begin{tabular}{|c|c|c|c|c|c|c|c|c|c|}
\hline \multirow{2}{*}{ Descriptive } & \multirow{2}{*}{$\begin{array}{l}\text { N } \\
\text { Stats. }\end{array}$} & \multirow{2}{*}{$\begin{array}{l}\text { Minimum } \\
\text { Stats. }\end{array}$} & \multirow{2}{*}{$\begin{array}{l}\text { Maximum } \\
\text { Stats. }\end{array}$} & \multirow{2}{*}{$\begin{array}{l}\text { Mean } \\
\text { Stats. }\end{array}$} & \multirow{2}{*}{$\begin{array}{l}\text { Std } \\
\text { Dev. } \\
\text { Stats. }\end{array}$} & \multicolumn{2}{|c|}{ Skewness } & \multicolumn{2}{|c|}{ Kurtosis } \\
\hline & & & & & & Stats. & $\begin{array}{l}\text { Std. } \\
\text { Error }\end{array}$ & Stats. & $\begin{array}{l}\text { Std. } \\
\text { Error }\end{array}$ \\
\hline Performance & 648 & & & & & & & & \\
\hline Male & & 1.29 & 5.00 & 3.811 & .7622 & -1.517 & .235 & 2.370 & .465 \\
\hline Female & & 1.33 & 5.00 & 3.819 & .71976 & -1.404 & .235 & 1.895 & .465 \\
\hline $\begin{array}{l}\text { Intention to } \\
\text { stay }\end{array}$ & 648 & & & & & & & & \\
\hline Male & & 1.30 & 5.00 & 3.857 & .71639 & -.1588 & .235 & 2.963 & .465 \\
\hline Female & & 1.21 & 5.00 & 3.855 & .77126 & -1.559 & .235 & 2.307 & .465 \\
\hline Commitment & 648 & & & & & & & & \\
\hline Male & & 1.27 & 5.00 & 3.801 & .7620 & -1.515 & .235 & 2.30 & .465 \\
\hline Female & & 1.30 & 5.00 & 3.800 & .7621 & -1.515 & .235 & 2.368 & .465 \\
\hline Absenteeism & 648 & & & & & & & & \\
\hline Male & & 1.30 & 5.00 & 3.856 & .7715 & -1.557 & .235 & 2.307 & .465 \\
\hline Female & & 1.21 & 5.00 & 3.855 & .7712 & -1.559 & .235 & 2.307 & .465 \\
\hline Fraud & 648 & & & & & & & & \\
\hline Male & & 1.30 & 5.00 & 3.857 & .71639 & -1.588 & .235 & 2.370 & .465 \\
\hline Female & & 1.21 & 5.00 & 3.855 & .77126 & -1.559 & .235 & 1.895 & .465 \\
\hline
\end{tabular}

Both in terms of the data presentation using pie chart for demographic characteristics of respondents, and the mean (x) score of organizational variables, it is evincing that banks employees are almost dominantly females, with ages between 20 - 40 years, who are also mostly single or unmarried. Also, on employee performance on the basis of award for best performance, the female do not have any significant score above the males, even with a higher numerical strength above the males.

On the intention to stay, the females tend to be low, as the analysis shows the male with a higher intention to stay. The females have a higher score of commitment to duty. This corresponds with Robbins \& Sanghi (2010) the female demonstrate obedient to work rules than males. The males score higher on decisional task, where high analytical skills are required for far-reaching decisions. Also, the males tend to have a high score for bank fraud than the female. This implies that bank fraud is mostly associated with male bank employees than their female counterparts.

\section{Myths and Realities of Gender Issues in Bank}

Societies and cultural collective consciousness are laced with perceptual inaccuracies which found expression in stereotypes (Horton, Leslie, \& Larson, 2006; Kottak, 2014; and Westen, 2000). This is often so because culture tends to limit the perception of individuals in a collective, by stipulating what it ought to be acceptable for people with a society. This affects almost boundless factors affecting a society. One of such consideration is the gender related issues which have affected society's view on sex roles, classified as feminine and masculine. Unfortunately, these society's held collective perceptions has found its way even to modern industrial organizations, like the banks as the case in Nigeria.

Drawing from the strength of this paper, it is a myth that female bank employees performs better than their male counterparts. This myth was disproven where despite the disproportional number of male and female employees, in favour of the female, the males were found that more performance merit award in all banks. It is also a myth that females are more stable in their jobs than males counterparts.

On the contrary, the males were found to be more stable. This tend to result from the feeling of urgency to take life responsibilities which permits less of time for moving from job to job, or from one occupation to another. This further implies that the males have the capacity to withstand workplace pressure, both emotionally and mentally. However, it is a reality that the females are endowed with natural appeals that can break boundaries to increase bank prospects, but this is short-lived. This tends to be so, because appeals dwell in the emotional realm, while financial decision involved in banking business are purely rational. Thus, in the long run, rationality overtakes emotions.

The myths about gender issues as it may also affect banks have made complex of perceptual realities. For instance, Horton, Leslie \& Larson (2006) argued that "sexism is a major social problem. Sexism refers to the set of beliefs that men are superior to women in general", but is a myth, because with due reference to qualities that 
lead to success in economic opportunity system, like the bank, this myth is found to merely go hand-in-hand with discrimination based on society's imposed sex-roles and expectations. Thus Westen (2000) argued that women suggested from long standing problem of personal identity, that most society do not permit its women to grow and fulfill their potentials as human beings.

Another complexity regarding the myths and realities of gender base difference in organizational life is leader-manager dichotomy. Women in professional and managerial occupations do not do much better in leadership. The theoretical explanation may be derived from McClalland's trichotomy of three need categories, involving power, affiliation and achievement. Men are often found to be high in power and achievement, while woman are high in affiliation and achievement. The men do better in leadership while women do better in managerial tasks.

\section{Conclusion and Implications}

There is a very strong indication that a combination of biological and social factors informed the consideration on the rampaging tendencies for the disproportionate employment of young unmarried women in Nigeria banks, when measured against the trend in the employment of men. It is obvious that employment in general spheres is based on competence, character, age, majorly. However, there characteristics are almost evenly shared between gender, with insignificant level of variations (Ines, Yap \& Whiting, 2013). Economic and social trends have combined to reform corporate attitudes and perceptions which affect the way in which these trends are adjusted or maladjusted to (Westen, 2000; and Kottak, 2014). For instance, the current development in Nigerian banks is suggestive of Mason, Czajka, Arber (1990) that sex-role attitudes have become notably more egalitarian, but can be debated whether the feminist helped cause the changes or is itself a result of the attitude changes, corresponding to Chance's (1988).

This disposition combined with the fact that most of the young women employed in these banks are mostly deployed in interface functions, like marketing, suggest the exploitation of the sex appeal to achieve business advantage. The sex appeal is a biological feature which societies or cultures have feminized with employers (banks) believing the more potential clients or customers can be attracted by women than men marketers. Unfortunately, the cultural and biological myth is played down in the long run where the males tend to perform better when indicator as best performing employee of the year is used.

However, being that natural given about sex difference do not significantly vary in industrial outcomes of male and female, the socio-culture creation in feminism and masculinism, according to Ferber \& Loab (2001) ahs affective the way women and men think of themselves. This view is supported in argument by Villamz (2001) that roles are given to people by society and organization, but when such roles are perceived as having natural fitness to certain natural categories, discrimination based on stereotypes abound.

Thus, the extreme discriminatory tendencies concerning gender and employments are superfluous and based on almost spurious perception, held in clothed immorality; the society has casted mould for gender activity or passivity. Horton, Leslie \& Larson (2006) thus contended that men have been expected to exercise power through authority and command; women have been expected to cultivate power through influence, sought through sex appeal, coquetry, flattery, and pandering to male egoism. However, while this contrast contains some perceptual exaggerations, average sex difference of these sorts are easily established.

Employers in banks believing in the strength of a women, have exaggerated the sex appeal, coquetry, flattery and pandering male egoism, to recruit more young girls who will invade the potential market for more deposits.

The implication therefore, is the womanization of Nigerian banks, where in the long run there will be less high level male executive. This tends to create a gap for male type authority, command, apt analytical skills etc, require of man in the banks. Also, if the sex appeal factor is strong, as known to be in male-female juxtaposition, then who takes care of the appeal required by female customers in the banks? Is the female bank market so negligible? To superintend the trend and save society from the ever expanding margin of sex-role discrimination, particularly employment. Three models of sex equality exist: (a) a pluralistic model in which sex division of labour persist, but categories of work performed by both sex are equally prestigious and rewarded; (b) an assimilationist model, in which women participate in society, equally with men; and (c) an androgynous model, in which all sex role difference in work, personality and behavior are cut to the irreducible minimum. Thus, this is suggested for other banks as well to enhance gender liberal workplace mobility, which will enhance the occupational advantages both gender in the banks.

\section{References}

Agundu, P.U.C. (2006) Corporate Womanization in Nigerian Commercial Banks, The Enterprise, 21(02), 18-30. Basow, S.A. (2000) Gender Stereotypes: Traditions and Alternatives, California: Book/Cole.

Black, M.M. \& Holden, E.W. (1998) The Impact of Gender on Productivity and Satisfaction Among Medical School Psychologists: Journal of Clinical Psychology in Medical Settings. March, 117-31.

Chance, P. (1988) Biology, Destiny and All that, Across the Board, July-August. 19-23. 
Eagly, A.H. \& Carli, L.I. (2009) Sex Researchers and Sex-Types Communications as Determinants for Sex difference in Influence-Ability: A Meta-Analysis of Social influence Studies. Psychological Bulletin, August, 1981.

Eketu, C.A. (2018) Stereotypic errors in gender-based discrimination: Under-utilizing organizational resource base. Academy of Social Science journal. 03 (05): 1182-86.

Feber, M.A. \& Loeb, J.W. (2010) Performance, Reward and Perception of Sex Discrimination Among Male and Female Faculty. American Journal of Sociology 78 (2): 995 - 1002.

Hewlett, S.A. \& Rashid, R. (2010) The Battle for female Talent in Emerging Markets. Harvard Business Review, May, 101-106.

Horton, Leslie \& Larson (2006) The Sociology of Social Problems. Englewood Cliffs, New Jersey: prentice-Hall, Inc.

Hyde, J.S. (2016) How Large are Cognitive gender Differences? American Psychologist, October, 1981. Pp. 892901.

Ines, Yap \& Whiting (2013) Sexual Discrimination and Harassment in the Hospitality Industry. International Journal of Hospitality Management.

Iyiola, A.R. \& Iyiola, A. (2009) Gender and Racial Differentials in Nigerian Banking Industry. Ninth Annual IBER \& TIC Conference Proceedings. Lag Vagas, 1-8, NV, USA.

Kottak, C.P. (2014) Anthropology: the Exploration of Human Diversity. New York: McGraw Hill.

Mason, K.O., Czajka, J.L. \& Arber, S. (2000) Changes in US Women's Sex Role Attitudes. American Sociological Review, 14 (2): 573 - 96.

Otuchikere, C. \& Ifeakundu, A. (2010) Nigeria: Banks sack - The Anguish, The agony. Allafrica.com, 15 January. Robbins, S.P. \& Sanghi, S.A. (2010) Organizational Behaviour, New Delhi: prentice Hall.

Villamez, W.J. (2001) Male Economic gains from Female Subordination: A Caveat and Reanalysis, Social Forces, $56(5): 626-41$.

Westen, D. (2000) Psychology: Mind, Brain, and Culture. Canada: john Wiley \& Sons, Inc. 